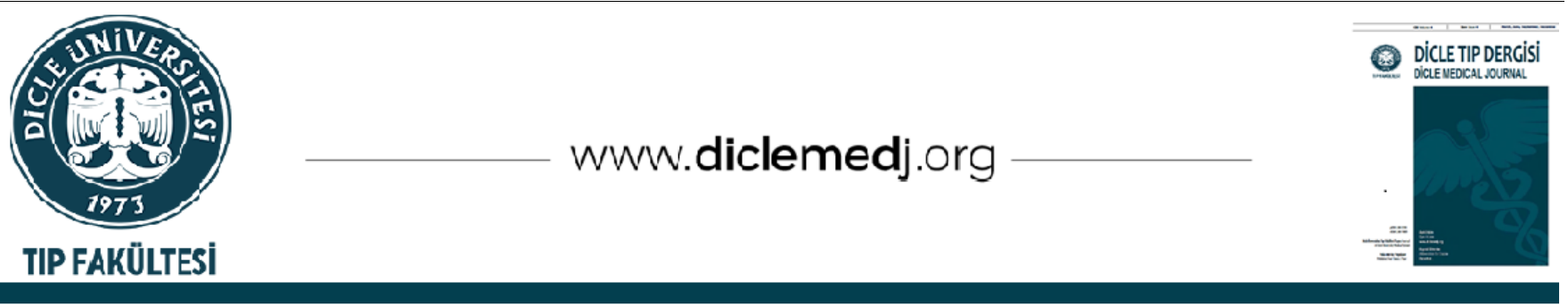

\title{
İleri Evre Medüller Tiroid Kanseri Tedavisinde Tirozin Kinaz İnhibitörü Kullanımı-Tek Merkez Deneyimi
}

\author{
Senar Ebinç iD 1, Zeynep Oruç iD 1, Zuhat Urakçı iD 1, Muhammet Ali Kaplan iD 1, Mehmet Küçüköner iD 1 , \\ Abdurrahman Işıkdoğan $\mathrm{ID}_{1}$
}

1 Dicle üniversitesi-Tıp Fakültesi İç hastalıkları-Tıbbi onkoloji, Diyarbakır, Türkiye

Geliș: 05.08.2020; Revizyon: 14.02.2021; Kabul Tarihi: 14.02.2021

$\ddot{\mathbf{O z}}$

Giriş: Medüller tiroid kanseri nadir görülen tiroid kanserlerindendir. Hastaların \%5-10 kadarı uzak metastaz ile başvurmaktadır. Metastatik hastalıkta göreceli olarak sitotoksik kemoterapilere dirençli olan bu kanser tipinde tirozin kinaz inhibitörleriyle uzun süre stabil yanıt elde edilebilmektedir. Bu çalışmada medüller tiroid kanserinde tirozin kinaz inhibitörleri kullanımı ve tedavi yanıtlarını incelemeyi amaçladık.

Yöntemler: 2006-2019 tarihleri arasında Dicle Üniversitesi Tıp Fakültesi Hastanesi Tıbbi Onkoloji Kliniği'ne başvurmuş olan lokal ileri veya metastatik medüller tiroid kanseri tanılı hastaların klinik özellikleri, aldıkları tedaviler ve tedaviye yanıtları retrospektif olarak incelendi.

Bulgular: Çalışmamıza 2006-2019 yılları arasında kliniğimize başvuran metastatik medüller tiroid kanserli 12 hasta alındı. Hastalarımızın 4'ü $(\% 33,3)$ kadın, 8'i $(\% 66,7)$ ise erkek idi. Her iki cinsiyette ortalama yaş 44.5 (24-67) yıldı. Sekiz (\%66) hastada sadece lenf nodu veya yumuşak doku metastazı varken, 3 (\%25) hastada hem kemik hem de visseral organ metastazı mevcut idi. Bir $(\% 8,3)$ hastada ise sadece kemik metastazı vardı. On iki hastamızın 2'sinde medüller tiroid kanseri multiple endokrin neoplazi 2A sendromunun bir parçası idi. Birinci basamak tedavide 5 hasta sitotoksik kemoterapi almıştı. Bu hastalarda progresyonsuz sağkalım 6 ay olarak izlendi. On iki hastamızın hepsi birinci veya ikinci basamakta tirozin kinaz inhibitörü kullanmıștı. Birinci veya ikinci basamakta vandetanib kullanmış olan 10 hastada medyan takip süresi 28 ay idi ve bu hastalarda medyan progresyonsuz sağkalım süresine henüz ulașılamamıştı. Geriye kalan iki hasta da sorafenib kullanmıștı. Herhangi bir tirozin kinaz inhibitörü kullanan hastalarda ise medyan progresyonsuz sağkalım süresi 40 ay olarak izlendi.

Sonuç: Medüller tiroid kanserinin tedavisinde tirozin kinaz inhibitörleri ve özellikle vandetanib kullanımı uzun süreli hastalık stabilizasyonu ve progresyonsuz sağkalım avantajı sağlamaktadır.

Anahtar kelimeler: Medüller tiroid kanseri, Tirozin Kinaz İnhibitörü, Vandetanib.

DOI: 10.5798/dicletip.887332

Correspondence / Yazışma Adresi: Senar Ebinç, Dicle Üniversitesi Tıp Fakültesi, Tıbbi Onkoloji kliniği, Sur/ Diyarbakır, Türkiye 21010 e-mail: senarebinc@gmail.com 


\title{
The Use of Tyrosine Kinase Inhibitors in Advanced Medullary Thyroid Cancer-Single Center Experience
}

\begin{abstract}
Objective: Medullary thyroid cancer is one of the rare thyroid cancers. Five-10\% of patients present with distant metastasis. In metastatic thyroid medullary cancers, which are relatively resistant to cytotoxic chemotherapies, longterm stable response can be achieved with tyrosine kinase inhibitors. We aimed to investigate the use of tyrosine kinase inhibitors and treatment responses in medullary thyroid cancer.

Methods: The clinical features, treatments, and responses to treatment of patients diagnosed with local advanced or metastatic medullary thyroid cancer who applied to Dicle University Faculty of Medicine, Department of Medical Oncology, between 2006 and 2019 were retrospectively analyzed.

Results: Twelve patients with metastatic thyroid medullary cancer who admitted to our center between 2006 and 2019 were analyzed. Four (33.3\%) of our patients were female and 8 (66.7\%) were male, mean age was 44.5 years (range:2467 years). Three patients (25\%) had both bone and visceral metastases, while eight patients (66\%) had only lymph node or soft tissue metastasis, one patient (8.3\%) had only bone metastasis. Two of twelve patients had multiple endocrine neoplasia 2A syndrome. Five patients received cytotoxic chemotherapy as first-line treatment. Progression-free survival was 6 months in these patients. All of patients used tyrosine kinase inhibitors as first-line or second-line treatment. Median follow-up of 10 patients who received vandetanib was 28 months and the median progression-free survival could not be reached in these patients. The remaining two patients used sorafenib. Median progression-free survival of the patients using any tyrosine kinase inhibitör was 40 months.
\end{abstract}

Conclusion: The use of tyrosine kinase inhibitors and especially vandetanib in treatment of medullary thyroid cancer provides long-term disease stabilization and progression-free survival.

Keywords: Medullary thyroid cancer, Tyrosine Kinase İnhibitor, Vandetanib.

\section{GíRiş}

Medüller tiroid kanserleri (MTK) tiroid parafoliküler hücrelerden kaynaklanan nöroendokrin tümörlerdir. Karakteristik olarak kalsitonin salgılayan bu tümörler tüm tiroid tümörlerinin yaklaşı $\% 1-2$ 'sini oluşturmaktadır. MTK çoğu zaman sporadik olarak ortaya çıkmakla birlikte, \%25 oranında multiple endokrin neoplazi 2 (MEN2) sendromunun bir komponenti olarak görülebilmektedir ${ }^{1}$. Hastaların $\% 95$ 'ine yakını tiroidde soliter nodül ile başvurmaktadır ${ }^{2}$. Bununla birlikte karaciğer, akciğer, kemik, yumuşak doku, beyin ve lenf nodu metastazları da izlenebilmektedir ${ }^{3}$. Yüzde 5-10 civarında hasta uzak metastaz ile başvurmaktadır ${ }^{1}$. Mikrometastazları tespit edebilmek için kalsitonin yararlı bir tümör markeri olarak kullanılmaktadır ${ }^{4}$ Ayrıca kalsitonin karsinoembriyonik antijen (CEA) ile birlikte metastatik hastalık takibinde kullanılmaktadır ${ }^{5}$.
Erken evre MTK hastalarında cerrahi tedavi yeterli olabilirken, ileri evre hastalarda sitotoksik kemoterapi seçenekleri gündeme gelmektedir. Diğer tümörlerde olduğu gibi medüller tiroid karsinomda da tümör proliferasyonu, anjiyogenez, invazyon ve metastazı tetikleyen tirozin kinaz mekanizmalarının rol alması nedeniyle tedavide vandetanib, kabozantinib, sorafenib, lenvatinib gibi tirozin kinaz inhibitörlerinin kullanımı standart hale gelmiştir ${ }^{1,6,7}$. Bu çalışmada medüller tiroid kanserinde tirozin kinaz inhibitörleri kullanımı ve tedavi yanıtlarını incelemeyi amaçladık.

\section{YÖNTEMLER}

Çalışmamıza 2006-2019 yılları arasında Dicle Üniversitesi Tip Fakültesi Tibbi Onkoloji Kliniğine başvuran tiroid kanseri tanılı hastaların dosyaları hastane arşivinden retrospektif olarak incelendi. Tiroid kanseri tanılı 597 hastanın kliniğimize başvurduğu 
görüldü. Bu hastaların 577'si $(\% 96,6)$ papiller veya foliküler tiroid karsinomu, 7'si (\%1,2) anaplastik tiroid karsinomu, 13'ü $(\% 2,2)$ medüller tiroid karsinomu histolojisine sahipti. Verilerine ulaşılan 13 MTK tanılı hastanın 12'si ileri evre hastalığa sahipti. MTK tanılı hastaların tanı esnasında CEA, kalsitonin, hemoglobin ve kreatinin değerleri retrospektif olarak incelendi. Hastaların klinik bilgileri, histopatolojik özellikleri görüntüleme sonuçları, aldıkları tedavi ve tedavi yanıtları incelendi. Çalışma için 04.06.2020/201 tarih ve karar numarası ile Dicle Üniversitesi Tıp Fakültesi etik kurulundan onay alındı. İleri evre medüller tiroid karsinomu tanısı olmayan hastalar çalışmaya alınmadı.

\section{İstatistik Analiz}

Verilerin istatistiksel olarak değerlendirmesinde SPSS 18.0 paket programı kullanıldı. Hasta özellikleri ve parametre sıklığını değerlendirmek için tanımlayıcı istatistikler, normal dağılıma sahip sayısal değişkenler için student-t test, normal dağllıma sahip olmayan veya non-parametrik değişkenlerin analizi için Mann-Whitney U testi, sağkalım analizleri için kaplan meier yöntemi kullanıldı. Güven aralığı \%95, p anlamlılık değeri $<0,05$ olarak kabul edildi.

\section{BULGULAR}

Çalışmamıza dahil edilen 12 MTK tanılı hastanın 4'ü (\%33) kadın, 8'i(\%67) erkek idi. Tüm hastaların ortalama yaşı 44,5 (24-67) yıl iken, ortalama yaş kadınlarda 30,5 (24-39) yll, erkeklerde ise 51,5 (3767) yıl idi. Her iki cinsiyette yaşlar arasında istatistiksel olarak anlaml fark vardı $(p=0.002)$. Hastaların hepsi kliniğimize başvurduğunda lokal ileri veya metastatik evre hastalığa sahipti. Vakaların 9'una (\%75) metastatik olmadan önceki dönemde tiroidektomi yapılmıştı, iki $(\% 16,7)$ hastaya tanı anında lokal ileri inoperable, birine $(\% 8,3)$ ise metastatik olması nedeni ile tiroidektomi yapılmamıştı. Dört (\%33) hasta postoperatif dönemde boyun kısmına adjuvan amaçlı olarak radyoterapi almıştı. Kliniğimize başvuru anında sekiz (\%66) hastada lenf nodu veya yumuşak doku metastazl, 3 (\%25) hastada kemik ve visseral metastaz, $1(\% 8,3)$ hastada ise sadece kemik metastazı vardı. Visseral organ metastazı olan hastaların hepsinde kemik metastazı ve karaciğer metastazı var iken buna ek olarak bir hastada akciğer metastazı, bir hastada ise sürrenal bez metastazı mevcut idi. İki $(\% 16,7)$ vakada MEN2A sendromu vardı. MEN2A komponenti olan vakaların birinde MTK'e ek olarak feokromasitoma ve paratiroid adenomu birlikte varken, diğerinde ise sadece paratiroid adenomu mevcuttu. Birinci basamakta $7(\% 58,3)$ hastaya sitotoksik kemoterapi [2 hastaya 4 haftada bir olmak üzere dakarbazin 250 $\mathrm{mg} / \mathrm{m}^{2}$ (1-5. günler arası) ve $5-\mathrm{FU} 450 \mathrm{mg} / \mathrm{m}^{2}$ (1-5. günler arası), 5 hastaya ise 3 haftada bir olmak üzere doxorubisin $40 \mathrm{mg} / \mathrm{m}^{2}$ (1.gün) ve sisplatin 60 $\mathrm{mg} / \mathrm{m}^{2}$ (1.gün)] verilmiști. Bu hastaların 1'inde $(\% 14,3)$ kısmi yanıt, 3'ünde $(\% 42,9)$ stabil yanıt gözlenmişken, $3(\% 42,9)$ hastada progresyon izlenmişti. İlk basamak kemoterapi ile medyan progresyonsuz sağkalım 6 aydı (Resim-I). On iki hastanın tümü birinci veya ikinci basamak tedavide tirozin kinaz inhibitörü kullanmıştı. Bu hastalardan 10 'u $(\% 83,3)$ vandetanib $300 \mathrm{mg} /$ gün, 2'si $(\% 16,7)$ sorafenib $800 \mathrm{mg} /$ gün kullanmıştı. İki hastada tedaviye başlandığı zaman ülkemizde vandetanib ve kabozantinib erişimi olmadığından dolayı sorafenib kullanılmıştı. Sorafenib kullanan hastalardan birisi erken dönemde kaybedildiğinden bu hastada yanıt değerlendirilmesi yapılmamıştı. Geriye kalan 11 hastanın 7'sinde (\%58) kısmi yanıt, 4'ünde $(\% 33,3)$ ise stabil hastalık durumu izlenmişti. Hastalarımızda tam yanıt izlenen veya progresyon gösteren olmamıştı. Hastaların ilk başvuruda ortalama kalsitonin düzeyleri 5978pg/ml (770-40.000), CEA düzeyleri ise $73 \mathrm{ng} / \mathrm{ml}$ (5-1000), hemoglobin $15,4 \mathrm{gr} / \mathrm{dl}$ ve kreatinin $0,73 \mathrm{mg} / \mathrm{dl}$ idi. Kalsitonin $(p=0.13)$, CEA $(p=0.18)$, hemogram $(p=0.39)$ ve kreatinin $(p=0.47)$ ile sağkalım arasında anlamlı ilişki izlenmedi. Detaylı bulgular Tablo.I'de belirtilmiştir. Herhangi bir TKİ kullanan hastalarda medyan progresyonsuz sağkalım 40 aydı (Resim-II). Vandetanib kullanan hastaların medyan takip süreleri 28 ay idi ve medyan PS süresine henüz ulaşılamamıştı (Resim-III). Vandetanibe bağlı olarak bir hastada grade 1 , bir hastada grade 2 cilt reaksiyonu, bir hastada grade 1 diyare, bir hastada ise grade 2 bulantı-kusma gelişmişti. Her üç hastada da tedaviyi aksatmayan yönetilebilir yan etki olarak değerlendirilmişti. 
Tablo I: Hastaların bazal karakteristik özellikleri

\begin{tabular}{|c|c|c|}
\hline \multicolumn{3}{|c|}{ Sayı ve yüzde oranları(\%) } \\
\hline \multicolumn{3}{|c|}{ Yaş (ortalama/yıl) } \\
\hline & Kadın & $30,5(24-39)$ \\
\hline & Erkek & $51,5(37-67)$ \\
\hline & Total & $44,5(24-67)$ \\
\hline \multicolumn{3}{|c|}{ Cinsiyet } \\
\hline & Kadın & $4(\% 33,3)$ \\
\hline & Erkek & $8(\% 66,7)$ \\
\hline \multicolumn{3}{|c|}{ MEN2 varlığı } \\
\hline & Var & $2(\% 16,7)$ \\
\hline & Yok & $10(\% 83,3)$ \\
\hline \multicolumn{3}{|c|}{ Primer tiroidektomi yapılan } \\
\hline & Evet & $9(\% 75)$ \\
\hline & Hayır & $3(\% 25)$ \\
\hline \multicolumn{3}{|c|}{ Metastaz lokalizasyonu } \\
\hline & LN veya YD & $8(\% 66)$ \\
\hline & Visseral + Kemik & $3(\% 25)$ \\
\hline & Kemik & $1(\% 8,3)$ \\
\hline \multicolumn{3}{|c|}{ Birinci basamakta aldığı $\mathrm{KT}$} \\
\hline & Sisplatin $\quad+$ & $5(\% 41,7)$ \\
\hline & Dakarbazin + 5-FU & $2(\% 16,6)$ \\
\hline & Almadı & $5(\% 41,7)$ \\
\hline \multicolumn{3}{|c|}{ Birinci basamak KT yanıtı } \\
\hline & Tam yanit & $0(\% 0)$ \\
\hline & Kısmi yanıt & $1(\% 14,3)$ \\
\hline & Stabil hastalık & $3(\% 42,9)$ \\
\hline & Progresyon & $3(\% 42,9)$ \\
\hline \multicolumn{3}{|c|}{ TKİ kullanımı } \\
\hline & Vandetanib & $10(\% 83)$ \\
\hline & Sorafenib & $2(\% 17)$ \\
\hline \multicolumn{3}{|c|}{ TKİ yanitı } \\
\hline & Tam yanıt & $0(\% 0)$ \\
\hline & Kismi yanit & $7(\% 58,3)$ \\
\hline & Stabil hastalık & $4(\% 33,3)$ \\
\hline & Progresyon & $0(\% 0)$ \\
\hline & Değerlendirilemeyen & $1(\% 8,3)$ \\
\hline \multicolumn{3}{|c|}{ Adjuvan Radyoterapi } \\
\hline & Aldı & $4(\% 33)$ \\
\hline & Almadı & $8(\% 67)$ \\
\hline \multirow[t]{5}{*}{ Tanıda } & laboratuar & \\
\hline & Kalsitonin $(\mathrm{pg} / \mathrm{ml})^{-}$ & $5978(770-40.000)$ \\
\hline & CEA (ng/ml) & $73(5-1000)$ \\
\hline & Hemoglobin (gr/dl) & $15,4(11,8-18)$ \\
\hline & Kreatinin (mg/dl) & $0,73(0,6-1,09)$ \\
\hline
\end{tabular}

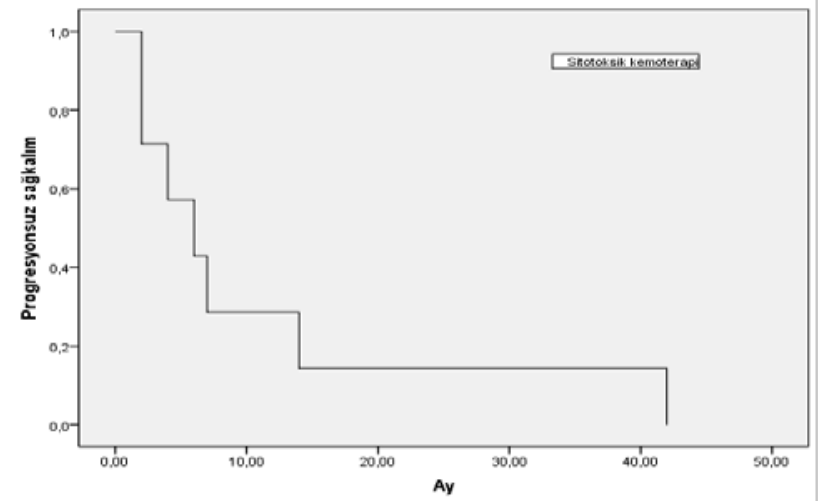

Resim 1: Birinci basamak tedavide kemoterapi kullanan hastalarda progresyonsuz sağkalım

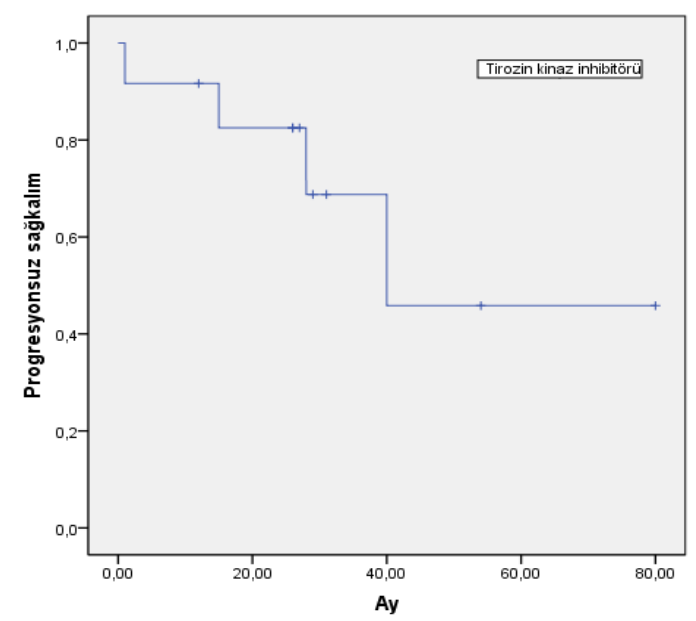

Resim 2: Herhangi bir tirozin kinaz inhibitörü kullanan hastalarda progresyonsuz sağkalım

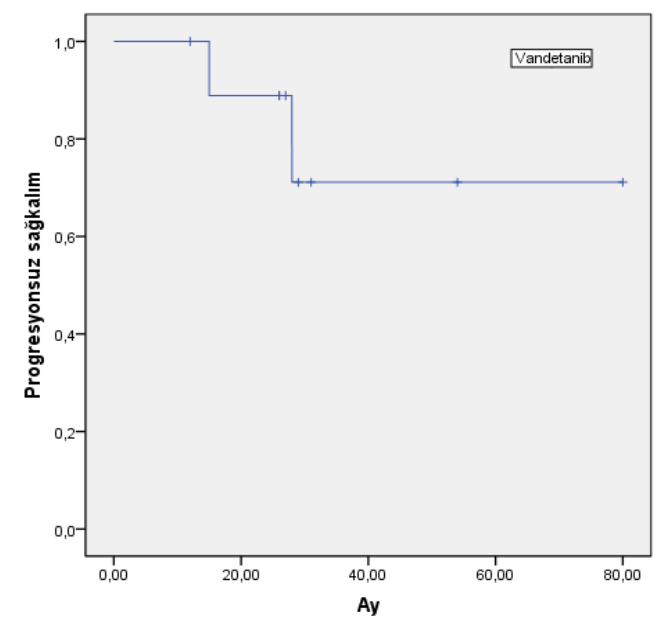

Resim 3: Vandetanib kullanan hastalarda progresyonsuz sağkalım 


\section{TARTIŞMA}

Tiroid kanserleri sık görülen kanserler arasında yer alsa da medüller tiroid kanserleri tüm tiroid kanserlerinin \%1-2 kadarını oluşturmaktadır 8,9 . Bizim çalışmamızda 597 hastanın 13'ü $(\% 2,2)$ medüller tiroid kanseri idi. Ancak kliniğimize genellikle ileri evre veya yüksek riskli hastalar refere edildiğinden bu oran tüm evrelerdeki tiroid kanser oranını yansitmamaktadır. Medüller tiroid kanserinin daha çok 4. ve 6 . dekatta sıklığı artmaktadır ${ }^{1}$. Çalışmamızda hastaların yaşları 30-50 yıl arasında yoğunlaşmaktaydı. Bir hasta 65 yaş üzerinde idi. Hastalarımızın ortalama yaşı 44,5 yıl idi. Kadın hastaların ortalama tanı yaşı 30,5 yıl iken, erkek hastalarda tanı yaşı 51,5 yıl idi. Kadın hastalar istatistiksel olarak anlamlı olarak daha genç yaşa sahipti. Medüller tiroid kanserinin tanı anında hastaların \%70'ine yakınında servikal lenf nodlarinda tutulum izlenmektedir. Vakaların \%15'inde üst hava ve sindirim yolu semptomları varken, vakaların sadece \%510 'unda uzak metastaz izlenmektedir ${ }^{2}$. Bizim de vakalarımızın \%66'sında literatürle uyumlu olarak lenf nodu veya yumuşak doku tutulumu mevcut idi. Hastaların \%25'inde ise visseral tutulum vardı. Metastatik olan hastalarda mikro-metastazların tespitinde kalsitonin düzeyleri önemli rol oynamaktadır. Bununla birlikte kalsitonin düzeyi kitle boyutu ile korelasyon göstermektedir ${ }^{2}$. MTK'de tümör markeri olarak kullanılabilecek bir başka parametre de CEA'dir. CEA medüller tiroid karsinom tanılı birçok hastada yüksek tespit edilmektedir ${ }^{10}$. Postoperatif kalsitonin ve CEA değerlerinin hızlı yükselişleri kötü prognostik göstergeler olarak kabul edilmektedir11,12. Çalışmamızda hastalarımızın hepsinde tanı anında kalsitonin düzeyleri yüksek idi. Ortanca kalsitonin düzeyi 5978pg/ml idi. CEA düzeyleri tüm hastalarımızda normal referans değerlerinin üzerinde izlendi. Ortanca CEA değeri $73 \mathrm{ng} / \mathrm{ml}$ idi. MTK vakaların yaklaşık \%75'inde sporadik iken, \%25 vakada bazı endokrin bozukluklarla izleyen MEN2 sendromunun bir komponenti olarak karşımıza çıkmaktadır ${ }^{9}$. Çalıșmamızda da literatüre yakın değerde; 12 hastanın 2'sinde (\%16,7) MEN2A sendromu tespit edilmiş ve tiroid medüller kanser MEN2A'nın bir komponenti olarak kabul edilmişti. Bir hastada MEN2A bulgularından feokromasitoma ve paratiroid adenomu, bir hastada ise sadece paratiroid adenomu izlenmişti.

Medüller tiroid kanseri tedavisinde sitotoksik kemoterapinin sonuçları tatmin edici değildir. Bununla birlikte doksorubisin, dakarbazin, fluorourasil, vincristin gibi ajanlar çeşitli kombinasyonlar şeklinde kullanılabilmektedir. Literatürde Dakarbazin ve fluorourasil kombinasyonlariyla \%15 hastada parsiyel yanit, \%50 hastada stabil yanıt izlenen çalışmalar mevcuttur ${ }^{13}$. Bizim çalışmamızda 5 hasta sisplatin ve doksorubisin kombinasyonu, 2 hasta ise dakarbazin ve fluorourasil kombinasyon tedavisi almıştı. Sitotoksik tedavi alan hastaların 1'inde (\%14,3) kısmi yanıt, 3'ünde $(\% 42,9)$ stabil yanıt elde edilmişti. Birinci basamak sitotoksik kemoterapi ile 6 aylık PS sağlanmıştı.

Metastatik tiroid medüller kanser tedavisinde başta vandetanib ve kabozantinib olmak üzere tirozin kinaz inhibitörleri etkin bir şekilde kullanılmaktadır. Tirozin kinaz inhibitörleri ile hastalık uzun süre stabilize edilebilmektedir. Sorafenib ile de 18 aylara varan PS bildirimleri olmuştur ${ }^{14}$. Tedavi başlandığı dönemde ülkemizde vandetanib ve kabozantinib erişimi olmadığından dolayı iki vakamızda sorafenib kullanılmıştı. Sorafenib kullanan bir vakamızda 40 aylık PS elde edilmişti. Diğer vaka bir ay içinde başka nedenden dolayı kaybedildiğinden yanıt değerlendirmesi yapılmamıştı. Diğer tarafta vandetanib ile çok başarılı sonuçlar bildirilmiştir. Tam yanıt oranları çok fazla izlenmezse de \%16 hastada parsiyel yanit ve \%53 hastada uzun süreli stabil yanıt elde edilebilmektedir ${ }^{15}$. Wells SA Jr. ve 
arkadaşlarının ileri evre veya metastatik medüller tiroid kanseri hastalarında yaptıkları 331 vakalık prospektif randomize, vandetanib plasebo karşılaştırmalı çalışmada; plasebo kolunda 19,3 aylık progresyonusuz sağkalım izlenirken, vandetanib kolunda medyan progresyonsuz sağkalıma ulaşılamamıştır ancak yapılan analizde bu çalışmada vandetanib ile PS 30,5 ay olarak öngörülmüştür ${ }^{16}$. Çalışmamızda 10 hasta vandetanib kullanmıştı. Bu hastaların 4'ünde (\%40) stabil yanıt, 6'sında (\%60) kısmi yanıt elde edilmişti. Vandetanib kullanan hastaların ortanca takip süreleri 28 ay idi ve medyan PS süresine henüz ulaşılamamıştı. Tüm TKİ kullanan hastalar beraber değerlendirildiğinde ise medyan PS 40 ay olarak izlendi. Dolayısıyla TKİ kullanan hastalarımızda ve özellikle vandetanib kullanmış olanlarda etkin ve başarılı bir hastalık stabilizasyonu sağlanmıştı. Vandetanib yan etkileri arasında ishal, döküntü, bulantı, hipertansiyon, baş ağrısı, yorgunluk, QT intervalinde uzama izlenebilmektedir [16]. Bizim vakalarımızın birinde hafif derecede ishal ve grade 2 cilt reaksiyonu, birinde grade 1 döküntü, birinde ise grade 2 bulantı-kusma izlenmişti. Her üç hastada da kolay yönetilebilir yan etki olarak değerlendirilmişti. Nadir olarak izlenen MTK'de tek merkezli çalışmalarda vaka azlığı nedeniyle sağlıklı istatistiksel sonuçlara ulaşmak her zaman mümkün olmamaktadır. Vaka sayımızın az olması çalışmamızın limitasyonları arasında idi. Çok merkezli ve yüksek vaka sayısı ile yapılacak çalışmalara ihtiyaç vardır.

Sonuç olarak; tiroid kanserleri arasında düşük sılklkta görülmekte olan metastatik medüller tiroid kanserlerinin tedavisinde tirozin kinaz inhibitörlerinin kullanımı düşük yan etki profili ile uzun süreli progresyonsuz sağkalım avantajı oluşturmaktadir.

Etik Kurul Kararı: Çalışma için 04.06.2020/201 tarih ve karar numarası ile
Dicle Üniversitesi Tıp Fakültesi etik kurulundan onay alındl.

Çıkar Çatışması Beyanı: Yazarlar çıkar çatışması olmadığını bildirmişlerdir.

Finansal Destek: Bu çalışma her hangi bir fon tarafından desteklenmemiştir.

Declaration of Conflicting Interests: The authors declare that they have no conflict of interest.

Financial Disclosure: No financial support was received.

\section{KAYNAKLAR}

1. Wells SA Jr, Asa SL, Dralle $\mathrm{H}$, et al. Revised American Thyroid Association guidelines for the management of medullary thyroid carcinoma. Thyroid. 2015; 25: 567-610.

2. Saad MF, Ordonez NG, Rashid RK, et al. Medullary carcinoma of the thyroid. A study of the clinical features and prognostic factors in 161 patients. Medicine (Baltimore). 1984; 63: 319-42.

3. Machens A, Hauptmann S, Dralle H. Increased risk of lymph node metastasis in multifocal hereditary and sporadic medullary thyroid cancer. World J Surg. 2007; 31: 1960-5.

4. Scheuba C, Kaserer K, Bieglmayer C, et al. Medullary thyroid microcarcinoma recommendations for treatment - a single-center experience. Surgery. 2007; 142: 1003-10.

5. Machens A, Hauptmann S, Dralle H. Medullary thyroid cancer responsiveness to pentagastrin stimulation: an early surrogate parameter of tumor dissemination? J Clin Endocrinol Metab. 2008; 93: 2234-8.

6. Wells SA Jr, Gosnell JE, Gagel RF, et al. Vandetanib for the treatment of patients with locally advanced or metastatic hereditary medullary thyroid cancer. J Clin Oncol. 2010; 28: 767-72.

7. Schlumberger M, Jarzab B, Cabanillas ME, et al. A Phase II Trial of the Multitargeted Tyrosine Kinase Inhibitor Lenvatinib (E7080) in Advanced Medullary Thyroid Cancer. Clin Cancer Res. 2016; 22: 44-53. 
8. Bozkurt K, Bektaş SS. Şırnak ilinde ameliyat edilen nodüler guatr olgularında tiroid kanseri görülme sıklığı. Dicle Tıp Derg. 2010; 37: 363-66.

9. Pacini F, Castagna MG, Cipri C, et al. Medullary thyroid carcinoma. Clin Oncol (R Coll Radiol). 2010; 22: 475-85.

10. Machens A, Ukkat J, Hauptmann S, Dralle H. Abnormal carcinoembryonic antigen levels and medullary thyroid cancer progression: a multivariate analysis. Arch Surg. 2007; 142: 289-93.

11. Barbet J, Campion L, Kraeber-Bodéré F, et al. Prognostic impact of serum calcitonin and carcinoembryonic antigen doubling-times in patients with medullary thyroid carcinoma. J Clin Endocrinol Metab. 2005; 90: 6077-84.

12. Kwon H, Kim WG, Jeon MJ, et al. Dynamic risk stratification for medullary thyroid cancer according to the response to initial therapy. Endocrine. 2016; 53: 174-81.
13. Nocera M, Baudin E, Pellegriti G, et al. Treatment of advanced medullary thyroid cancer with an alternating combination of doxorubicinstreptozocin and 5 FU-dacarbazine. Groupe d'Etude des Tumeurs à Calcitonine (GETC). Br J Cancer. 2000; 83: 715-8.

14. Lam ET, Ringel MD, Kloos RT, et al. Phase II clinical trial of sorafenib in metastatic medullary thyroid cancer. J Clin Oncol. 2010; 28: 2323-30.

15. Robinson BG, Paz-Ares L, Krebs A, et al. Vandetanib (100 $\mathrm{mg}$ ) in patients with locally advanced or metastatic hereditary medullary thyroid cancer. J Clin Endocrinol Metab. 2010; 95: 2664-71.

16. Wells SA Jr, Robinson BG, Gagel RF, et al. Vandetanib in patients with locally advanced or metastatic medullary thyroid cancer: a randomized, double-blind phase III trial. J Clin Oncol. 2012; 30: 134-41. 